\title{
I wake up screening
}

\author{
Tony Delamothe UK editor
}

BMJ

The topic of medical screening generates heat and light. Let's start with the light.

The proportion of UK women who have undergone cervical screening has been falling, particularly among young women. Less invasive methods than speculum examination might be an answer, but are they as trustworthy? This week Neha Pathak and colleagues report a meta-analysis comparing the accuracy of human papillomavirus (HPV) testing of urine samples with cervical samples obtained by a doctor (BMJ 2014;349:g5264, doi:10.1136/bmj.g5264). The results were promising enough for our editorialists Henry Kitchener and Gemma Owens to recommend further evaluation (BMJ 2014;349:g5542, doi:10. 1136/bmj.g5542).

Another good news story: cell free fetal DNA can now be isolated from the maternal circulation and the baby's rhesus status ascertained from just $20 \mathrm{~mL}$ of maternal blood. In their research paper Lyn Chitty and colleagues show that fetal $R H D$ genotyping after 24 weeks' gestation can be used to direct immunoprophylaxis to $\mathrm{RhD}$ negative women predicted to be carrying an $\mathrm{RhD}$ positive baby - thereby reducing unnecessary exposure to anti-RhD immunoglobuliin (BMJ 2014;349:g5243, doi:10.1136/bmj.g5243).

Both of these look like positive developments. But this week's journal also has examples from screening's dark side. Take blood pressure measurement, probably the most performed screening test in modern medicine. It's been phenomenally successful: an estimated $40 \%$ of the world's population has hypertension. (The ever dropping threshold for diagnosing the condition keeps the numbers rising.) Yet great uncertainty surrounds the value of making the diagnosis of mild hypertension, which afflicts a fifth of the world's population. Most people with mild hypertension are treated with drugs, say Stephen Martin and colleagues (BMJ 2014;349:g5432, doi:10. 1136/bmj.g5432). Yet evidence indicates "no net benefit from drug treatment of mild hypertension in people without the higher risks of diabetes or chronic heart disease." What's going on? This latest instalment in The BMJ's Too Much Medicine series tries to join the dots.

More from the dark side: three years ago we published Susan Bewley's open letter to England's then cancer tsar, Mike Richards, calling for an independent review of the evidence for breast cancer screening (BMJ 2011;343:d6894, doi:10.1136/ bmj.d6894). He immediately agreed to the review (BMJ 2011;343:d6843, doi:10.1136/bmj.d6843), although it's unclear whether anything has changed since it reported.

Now Bewley and like minded souls have set their sights on the UK mammography screening age extension trial. Their beefs include a chief investigator who ignores questions or obfuscates, and who both runs the national programme and chairs the (non-independent) trial steering committee (BMJ 2014;349:g5601, doi:10.1136/bmj.g5601). An eight page study protocol, produced only after repeated freedom of information requests, contains two references and has no statistical analysis plan. The most important outcomes, all cause mortality and morbidity (mastectomy), are not mentioned. The governance and oversight are opaque. The original research ethics committee did not contain a statistician. The current one has twice rejected proposed substantial amendments and expressed concerns about consent. There is no assurance that participants even realise that they are in a randomised trial.

Can the trial survive unscathed? I wouldn't put my money on it. A Dutch study presented at this week's Preventing Overdiagnosis conference (supported by The BMJ's Too Much Medicine campaign) and published on thebmj.com (BMJ 2014;349:g5410, doi:10.1136/bmj.g5410) sheds useful light on the subject. Its findings indicate that extending the age range for breast screening to 75 probably isn't worth it. For every case of advanced cancer detected by screening among $70-75$ years olds, around 20 "extra" overdiagnosed early stage cancers were picked up.

Mention of screening and dementia in the same sentence is a guarantee that sparks will fly. In his letter Martin Brunet (BMJ 2014;349:g5629, doi:10.1136/bmj.g5629) supports our columnist Margaret McCartney (BMJ 2014;349:g4791, doi:10. 1136/bmj.g4791), who argued that "case finding" in dementia was simply screening minus an evidence base. In other words, a fudge, says Steve Iliffe (BMJ 2014;349:g5634, doi:10.1136/ bmj.g5634).

Cite this as: BMJ 2014;349:95706

๑ BMJ Publishing Group Ltd 2014 